Research Article

\title{
The Prestressed Track Beam Testing Technology of Shanghai Electromagnetic Levitation Train
}

\author{
Qing-biao WANG ${ }^{1,2,3,}$, Cong ZHANG ${ }^{1}$, Xiao-kang WEN ${ }^{1}$ and Zhen-yue SHI ${ }^{1}$ \\ ${ }^{1}$ Department of resource and civil engineering of Shandong University of Science and Technology, Taian, Shangdong province, \\ 271019, China \\ ${ }^{2}$ State Key Laboratory of Geomechanics and Geotechnical Engineering, Institute of Rock and Soil Mechanics, Chinese Academy of \\ Sciences, Wuhan,430071, China \\ ${ }^{3}$ Shandong Hualian Mining CO.,LTD, Yiyuan, Shangdong province, 251000, China
}

Received 15 May 2013; Accepted 25 July 2013

\begin{abstract}
Shanghai electromagnetic levitation train (maglev) is the first one that is constructed and operated commercially in the world. Many technological problems have to be tackled during its construction, and the most difficult problem in the civil engineering part is the making of prestressed track beam. It requires high precision because of its special function. The stretching control of the pre-tensioning force and the post-tensioning force in the making of prestressed track beam is most important during the construction. This paper introduces and analyses the technical features of vibrating wire sensors as well as the development, the research and the application of force sensor for pulling force measurement of anchor cable.
\end{abstract}

Keywords: Eelectromagnetic Levitation Train (maglev), Prestressed,track beam, Vibrating Wire Sensor(VWS), Force Sensor For Pulling Force Measurement Of Anchor Cable

\section{Introduction}

The experimental line of Shanghai electromagnetic levitation train is $30 \mathrm{kms}$ long, expending from long yang subway station in the west to the Pudong international airport in the east. With the speed of $430 \mathrm{~km} / \mathrm{h}$, it takes only 8 minutes from the west to the east with an interval of 10minites. There are in all 2551 track beams, the length of which is $12 \mathrm{~m}, 21 \mathrm{~m}, 24 \mathrm{~m}$ and $50 \mathrm{~m}$ respectively. The twisted wire in the beam is the high strength and low laxity 270 one with the diameter of $15.42 \mathrm{~mm}$, the acreage of $140 \mathrm{~mm}$, and the standard strength of $1860 \mathrm{MPa}$. The technical standards are in accord with those stated in ASTMA416M-98 and GB/T5224-1995.

\subsection{The selection of the track beam}

Nowadays, judging from the electromagnetic levitation technology in Japan and Germany, there are 3 types of track beam that are technologically mature: the concrete one, the steel structure one and the refined concrete complex one. Compared and analysed from the aspects of operation, abrasion, noise, cost, transportation and, heat bulge, the refined concrete complex one is the best choice., because it not only has the advantages of the concrete one: high rigidity, noise absorption but also has the advantage of the steel structure one: high precision .Besides, it can make the construction easier by making the concrete prestessed

*E-mail address: 1349725165@qq.com

ISSN: 1791-2377 @ 2013 Kavala Institute of Technology. All rights reserved. trackbeam and its steel parts respectively.

\section{$1.2 \mathrm{key}$ data of the track beam}

(1) Designed standard span of beam: $21.00 \mathrm{~m}, 24.00 \mathrm{~m}$.

(2) The height is $2209 \mathrm{~mm}$, the top of the beam is $2800 \mathrm{~mm}$ wide and the widest part of the bottom is $3000 \mathrm{~mm}$.

(3) The system of pre-tensioning and post-tensioning forces adopted is original in our country. And the high strength and low laxity 705 twisted wire adopted matches the stretching instruments.

(4) The concrete used, c60, is quick-stiffen, of high strength, high flowage and low shrink. And its flexible modulus Ea>36.0 Gpa.

\subsection{Features of track beams}

(1) Its high precision and high difficulty in production. The train speed is about $120 \mathrm{om} / \mathrm{s}$ over the track beam . So the production of the beam must be very precise, which is very difficult to meet .The error of prestressed track beam permitted is $5 \mathrm{~mm}$ in length, $2 \mathrm{~mm}$ in height and $2 \mathrm{~mm}$ in width The error of the connectors and embedded steel piece are $2 \mathrm{~mm}$ in the three dimensions .he error during in the assembly are $0.2 \mathrm{~mm}$.

(2) Its multi-function of the beam of load bearing, guiding, driving, etc. The long stator loops attached to the track beam bear all the loads from the beam.

(3) The control of the beam shrink and creep is strictly required. 
1.4 The key technical problems during the construction Because of the special of the prestressed track beam and lack of experience in china, there are many technical problems to solve, such as the making of the molding plate, the preparing of C60 concrete, the design of the adjustable stand that can eliminate the effects caused by the descent of the ground base etc. Among all those problems, the most important one is the stretching control of the prestressed force. Because the prestressed force includes the pre-tensioning force and the post-tensioning force and there is no prior example to follow, the stretching control of the prestressed force will count for the succss of the design and the track beam's final shape.

The most commonly used way of the stretching control of the prestressed force is the use of hydraulic lifting jack pressure meter. However, it cannot meet the requirement of the project because of its low precision. Therefore, it is urgent to design the force sensor for pulling force measurement of anchor cable with wide range, high precision and long-term stability. So, Shandong University of Science and Technology and Shanghai Institute of Constructon made joint efforts to take this responsibility, and decide to adopt the vibrating wire sensor after analysis and research.

\section{The advantages of the Vibrating-wire Sensors}

There are many devices that can monitor pressure and force in coal mine nowadays, and the most commonly used ones fall into two categories: the force sensors with resistance strain gauge and vibrating-wire sensors. Both have their advantages and disadvantages. However, applications to the geotechnical engineering have showed that the advantages of the vibrating-wire sensors are comparatively more obvious. They are of high accuracy and reproducibility and are water resistance, so they can be used in harsh environment with long life-span as well as long-term stability. The structure is simple and reliable, so they are easily made and installed. Based on electromechanical coupling resonance, their outputs, frequency signals, can be transmitted over a long distance without distortion and measured directly in digital systems. Thus, it is easy to realize multi-point remote monitoring with this kind of sensors. Moreover, they can be cheaply made in durable steel structure. As the additional vibrating-wire frequency device is small and portable, and the data can be read directly, they are suitable for using on site[1].

\section{Structure and operating principle of Vibrating-wire} Sensors

\subsection{Structure of Vibrating-wire Sensors}

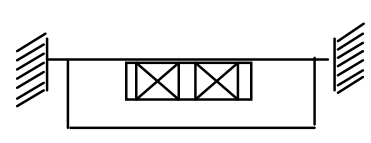

Vibrating wire

(a) Horizontal wire type

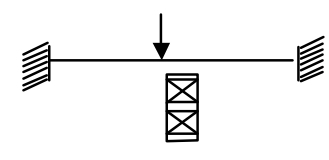

Vibrating wire (b) Vertical wire type
Fig.1. Structural diagrams of Vibrating-wire

The structure of VWS can be classified into two types: (a) Horizontal wire type. (b) Vertical wire type. The Structural diagrams are shown in Fig.1.
3.2 Operating principle of Vibrating-wire Sensors The principle of Vibrating-wire Sensors is shown in Fig.2

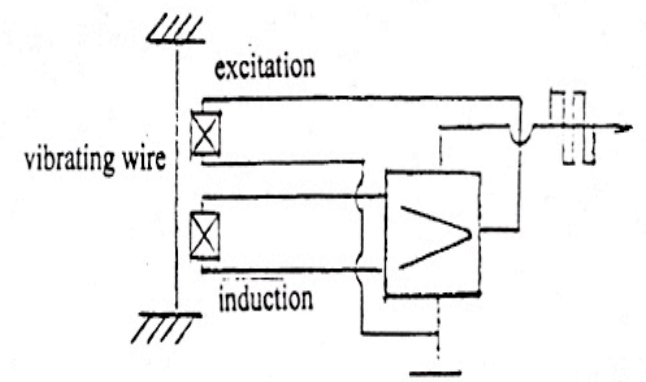

Fig.2. Operating Principle of Vibrating-wire

The feeble vibration of the wire results to an electromotive force (EMF) in the induction coil. The EMF is amplified by the excitation circuit to produce a pulse feed back to excitation coil, intending to increase vibration of the wire. If the closed electromechanical loop is designed properly, the continuous vibration is sustained at the natural frequency of the wire[2,3]. Then, the excitation circuit gives out an electrical signal with the same frequency as the above one. Through calibrating the relationship between the output frequency $f$ and the applied force F, F can be calculated after measuring $\mathrm{f}$.

\section{Mathematical model of Vibrating-wire Sensors}

The commonly used mathematical model of Vibrating-wire Sensors is defined by $\mathrm{F}=\mathrm{K}$ ( $\mathrm{f} 2-\mathrm{fo} 2)$ (1) Where $\mathrm{F}$ is physical variable (force, pressure etc.); $\mathrm{K}$, coefficient; $\mathrm{f}$, corresponding output frequency to $\mathrm{F}$; $\mathrm{fO}$, initial frequency when $\mathrm{F}=0$.

However, the fitting error of equation (1) is relatively large for most Vibrating-wire Sensors. Therefore, it needs to be modified. There are two methods to do so. One is based on $\mathrm{K}$ a function of $\mathrm{f}$. Another assumes $\mathrm{K}$ constant and a modified tern like a constant times (f-f0) should be added. Which one is more reasonable? To answer this question, Let us examine the derivation process of equation (1).

\section{The design of vibrating wire sensors for pulling force measurement of anchor rope}

The sensors for pulling force measurement of anchor rope is used to stretching control of the prestressed force and to test and monitor the changes of it[4]. Because of the high requirement of precision, long-term reliability, stability, temperature stability and wet resistance, a series of technical problems should be solved.

As the load is over $1000 \mathrm{KN}$, if the traditional direct measurement is adopted, the results would not be reliable because the large stressed force will change gradually, leading to the shift of zero point and sensibility. And due to the heavy weight, large size, difficulty in heat processing, the performance cannot be assured. Therefore, the indirect measurement is adopted[5,6]. The design is a combination of a hollow hydraulic pressure shift oil cylinder and a hydraulic high-pressure sensor, which is showed in Fig 3. 


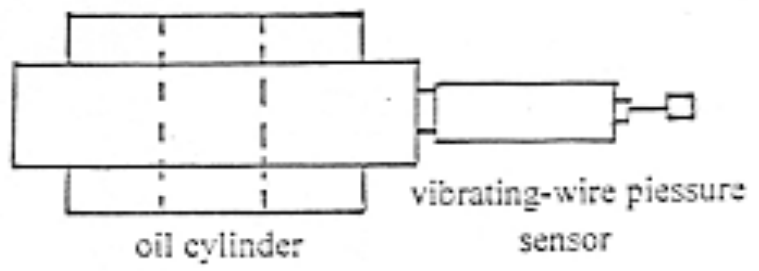

Fig.3. Force sensor for pulling force measurement of anchor rope

The design of oil cylinder will affect its performance. Although the problem of airproof can be ignored by steel plate welding, the accuracy, repetition, stability and other performances cannot work well, so it cannot be used. About 5 , ooo shifting hydraulic pressure measurement oil cylinders, combination of piston and cylinder, have been used in the test of single hydraulic pressure holder load. Due to rich practical experience in keeping airproof and good performance, this is the best choice. The fellow points should be paid more attention.

(1) For effect of airproof, two airproof rings should be used. If the first is broken the other will work.

(2) To raise the ability of anti eccentric load and reduce the eccentric load, the height of piston and the rigidity and the precision of the cylinder and piston should be improved

(3) High quality liquid medium, ropy and easy to airproof and lubricities should be chosen[7].

\section{Calibration testing of vibrating-wire force sensor for pulling force measurement of anchor cable.}

The 10sets of force sensor for pulling force measurement of anchor cable. Designed and produced in 2001,were mainly used in prestressed force testing in the Shanghai electromagnetic levitation train and the experimental measurement of steel twisted wire, and were tested and calibrated in National Institute of Metrology.

Standard measurement: $5 \mathrm{MN}$ norm ergometer

Degree of uncertainty: $3 \times 10$

Testing environment: tempreture: 24 humility: $52 \% \mathrm{RH}$

Testing basis: JJG391-1985 Pilot Statutes of load Sensors Testing. The results are shown in the Table 1:

Table 1 The testing results of National Institute of Metrology P.R.China

\begin{tabular}{c|c|c|c|c|c}
\hline No. & type & $\begin{array}{c}\text { range } \\
(\mathrm{KN})\end{array}$ & $\begin{array}{c}\text { hysteresi } \\
\mathrm{s}\end{array}$ & unrepeatability & $\begin{array}{c}\text { Full scale } \\
\text { error }\end{array}$ \\
\hline 035 & $\mathrm{MGH}-4000$ & 4000 & $0.5 \% \mathrm{FS}$ & $0.04 \% \mathrm{FS}$ & $0.05 \% \mathrm{FS}$ \\
\hline 033 & $\mathrm{MGH}-4000$ & 4000 & $0.9 \% \mathrm{FS}$ & $0.2 \% \mathrm{FS}$ & $0.05 \% \mathrm{FS}$ \\
\hline 032 & $\mathrm{MGH}-2500$ & 2500 & $0.03 \% \mathrm{FS}$ & $1.3 \% \mathrm{FS}$ & $0.12 \% \mathrm{FS}$ \\
\hline 020 & $\mathrm{MGH}-2500$ & 2500 & $0.06 \% \mathrm{FS}$ & $0.9 \% \mathrm{FS}$ & $0.16 \% \mathrm{FS}$ \\
\hline 021 & $\mathrm{MGH}-2500$ & 2500 & $0.07 \% \mathrm{FS}$ & $1.2 \% \mathrm{FS}$ & $0.2 \% \mathrm{FS}$ \\
\hline 026 & $\mathrm{MGH}-2500$ & 2500 & $0.06 \% \mathrm{FS}$ & $1.0 \% \mathrm{FS}$ & $0.16 \% \mathrm{FS}$ \\
\hline 028 & $\mathrm{MGH}-2500$ & 2500 & $0.08 \% \mathrm{FS}$ & $0.8 \% \mathrm{FS}$ & $0.08 \% \mathrm{FS}$ \\
\hline
\end{tabular}

As we can see from the table, its precision, as high as $0.05 \% \mathrm{Fs}$, makes it able to make 0.1 level products; its reproducibility is excellent; its uncertainty is $3 \times 10$. The results are certain and credible.
The vibrating-wire force sensor for pulling force measurement of anchor cable so produced is mainly used to calibrate the pre-tensioning force and the post-tensioning force prestressed devices used in the track beam of electromagnetic levitation train, that is the calibration of the lifting jack pumping station pressure meter[8]. When the relations between the tensioning force of steel twisted wire and the pumping station pressure, the pressure meter can be used to monitor the post-tension method prestressed force to ensure the stretching control of the prestressed force., as is shown in Fig4. Meanwhile, it was also used in the prestressed material laboratory in Shanghai Institute of Construction in the mechanical experimental test of the steel twisted wire and anchorage assembly.

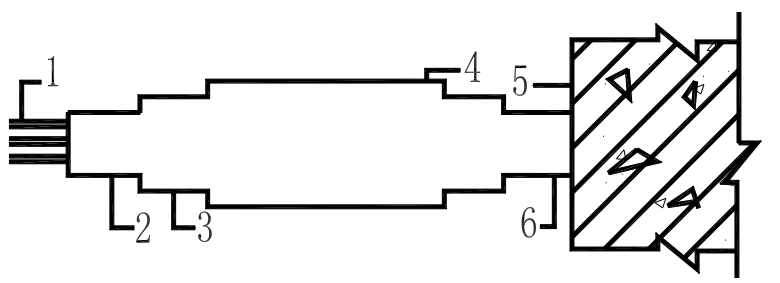

Fig.4. Position of force sensor for pulling force measurement of anchor rope

1.twisted wire; 2.tool anchorage; 3.piston; 4.oil cylinder; 5.functional anchorage; 6.concrete

\section{Conclusions}

The vibrating-wire force sensor for pulling force measurement of anchor cable, designed and produced by Shandong University of Science and Technology, has played an important part in the prestressed track beam testing in the Shanghai electromagnetic levitation train, the making and installation of the track beam, and the stretching control of the prestressed force. Applications to the geotechnical engineering have shown the advantages of it. It is of high precision and has equaled the international level. The reasonable design of the bearer structure can eliminate the negative effects of eccentric load and let all the load fall on the load transfer devices. The wide range of the force sensor for pulling force measurement of anchor cable can reach $1000 \mathrm{t}$ or above. Moreover, it can work in the harsh environment and the data can be read directly, so it's easy and convenient to operate.

\section{Acknowledgements}

This work was financially supported by:

(1) the Open Research Fund of State Key Laboratory of Geomechanics and Geotechnical Engineering, Institute of Rock and Soil Mechanics, Chinese Academy of Sciences, under grant NO.2012003.

(2) A Project of Shandong Province Higher Educational Science and Technology Program (J12LH03).

(3) China's Post-doctoral Science Fund, under grant NO. 2012M521365.

\section{Applications of prestressed track beam testing}




\section{References}

1. Deng Tie-liu, Wang Qing-biao, Hu Jian-ming, new developments of self-excitation vibrating-wire sensor technology and new type force sensor for pulling force measurement of anchor cable. [J]. Chinese Journal of Rock Mechanics and Engineering. 2001, 20 (Special Edition), 1769-1771.

2. Ma Jun-ting, Deng Tie-liu, Zheng Feng-long. Steel Wire Sensor Used for Measuring Physical Force. China: ZL96156680.5

3. Cui Yu-liang, Deng Tie-liu, Yu feng. Resonant Mode Sensor Theory and Testing Techniques, Beijing: Coal Industry Press, 1997,1-20.

4. Zheng Feng-long, Deng Tie-liu, Zhao Zhen-yuan. Double Coil Steel Wire Exciter .China: ZL9323121.8, 1993.
5. Deng Tie-liu, Yu Feng, Deng Wei. Big Measurement Range Selfexcited Vibrating Sensor and Relevant Techniques. [J], Sensor Techniques, 2001, 9, 41-46.

6. Wang Qing-biao, Lv Ai-zhong, Deng Tie-liu, Application and study of long-term force sensor for pulling force measurement of anchor rope $[\mathrm{J}]$ Rock and Soil Mechanics, 2003.24 (Special Edition): $150-153$.

7. Deng Tie-liu, Zhao Sheng-li, ZhaoZhen-yuan, High accuracy of vibrating string type sensor $[\mathrm{J}]$. Journal of shandong university of science and technology 2010,29,52-57.

8. Zhang Han-ping, Wang Tao, Vibrating wire sensor in the application of long-term detection [J] scientific decision-making. 2008 (11), 206-207. 